\title{
Design And Trial Selective Attention Computer-Based "Letvis" Program For Children With Attention Deficit Disorder
}

\author{
Naeila Rifatil Muna ${ }^{1}$, Laila Qodariah $^{1}$, Ratna Jatnika ${ }^{1 *}$, Urip Purwono ${ }^{1}$, Juke R \\ Siregar $^{1}$ \\ ${ }^{1}$ Department of Psychology, Padjadjaran University, Jl. Km.21 Jatinangor, Bandung, West Java, Indonesia. \\ ${ }^{*}$ Corresponding author. Email: ratna@ unpad.ac.id,
}

\begin{abstract}
Generally, children with Attention Deficit Disorder (ADD) are easily distracted and display lower selective attention abilities by numerous activities not related to the task at hand. This can cause various problems in their academic and social lifestyle. These attracted researchers into conducting a research aimed at designing a Letter Visual Search (LetViS) programs for children diagnosed with hearing deficiency. The first study aims at designing selective attention LetViS software using computer programs and psycho-education approaches. An exploratory research method was used in obtaining data. The designed software is a series of repetitive activities that require children to respond to target stimuli, while ignoring the non-target ones. The second study is a selective attention trail program that uses a time design series with a purposive sampling method. D2 test was used to measure the selective attention, while data was analysed using visual inspection techniques. The results of data analysis in Study II show that the LetViS program can be used to enhance the selective attention syndrome in children with ADD. Increasing selective attention to foster children's selfawareness in changing less effective behaviour will be more effective in maintaining attention to the target stimulus.
\end{abstract}

Keywords: Selective attention, computer program, psychoeducation, attention deficit disorder.

\section{INTRODUCTION}

Children with attention deficit disorder (ADD) show a number of behaviours with the major ones being inattention, hyperactivity, and impulsivity. If the main characteristic is inattention, then the child will find it difficult to pay attention (APA, 2013). Inattentiveness would lead to ease distraction by varieties of stimuli that are most times not related to the task at hand. This shows these set of children have lower selective attention abilities compared to others. The result can be problematic to their academic and social life.

Paying selective attention is to focus their attention on specific stimuli that are appropriate to the task of facing various irrelevant distractions or stimuli that must be eliminated in order to carry out the objective correctly and completely (Solhberg \& Mateer, 2010; Flick, 2010). These irrelevant stimuli can be external namely vision, sound, or activity, and internal for instance anxiety, trouble, uneasiness, fear, misery, and lots more. The inability or failure of children living with ADD to perform selective attention is owing to the fact that they tend to pay attention to all types of stimuli and electro- physiologically fails to be selective or focus on relevant targets. (Gomes et al, 2011).

With the evolution of the computer, computational resources, internet and digital technology media era, the need to improve children's ADD selective attention using computerized training program arises. This medium, uses computerized training programs to enhance the hearing ability of children diagnosed with ADD. Designing computer game programs gives them the opportunity to deal with this inconsistency in a creative way. Carrying out these tasks becomes a fun activity, and encourages them to participate in the learning process. The most important thing based on the results of the study is that computer games can be designed and used to improve kids' cognitive abilities, in children who experience ADD. One of such ability is attention to details (Veenman, Bavelaar, De Wolf, \& Van Haaren, 2014). The process of conducting training using a computer requires a reaction process or feedback. Therefore, researchers are interested in designing programs to improve selective attention abilities for ADD children using the psycho-education approach (Vallet, 1976) in 
modifying the behaviour and principles of repetition in attention training programs (Flick, 2010).

This computer program uses visual stimulus because most $80 \%$ of information received by humans is through visual sensations (Stainberg, 2006). The visual stimuli of the letters used have same shape. This is based on the attention process theory of Schneider and Shiffrin (1977). According to their theory, when someone searches for letters using selective attention processes, a serial controlled process occurs because the child will be asked to recognize or find a specific target letter and ignore the collection of non-target letters. As a result of this, researchers designed training programs using visual letter stimuli in order to ameliorate the selective attention abilities inherent the program. Next the researcher used the term Letter Visual Search (LetViS) to name this selective attention program.

The psycho-education approach is used in the LetViS training program for children with GPP to emphasize the growth of children's self-awareness regarding ineffective behaviours that hinders the completion of tasks and their abilities to develop effective behaviours. In the LetViS program, the target and non-target stimulus were randomly generated repeatedly. Through this game, children are trained to sort between target and non-target stimuli. Non-target stimuli act as distractions and must be ignored. Repetitive training makes the child learn to direct their behaviours so that they can produce effective behaviours, thereby, reducing the ineffective ones which is a manifestation of selective attention ability.

In children with ADD, there is usually an imbalance of neurotransmitters which occurs in the frontal lobe. As a result, children do not only respond to stimuli that are relevant to the task, but those not related to the task. They tend to respond to almost all the stimuli they come across (Dawson \& Guare, 2010).

Based on the background of the problem, the purpose of this study was to design and obtain an initial form of LetViS program training, which has been empirically tested to enhance selective attention skills in children. With this system a person can direct his behaviour to the expected goals through the following abilities; the ability to delay responses, stop irrelevant responses, and ability to control distraction.

The LetViS program is expected to add a particular type of treatment to improve the ability of selective attention in children with ADD. To the community practitioners, the psychologist, and the Child Clinical Psychologist, parents and LetViS teachers can play a vital role in training the selective GPP attention skills in children. LetVis's selective attention program using computers provides an opportunity for children with ADD to practice with one form of stimulus in a more enjoyable way. Children are provided with the right attention skill strategies in dealing with tasks that must be completed correctly.

\section{METHOD}

This research methodology was conducted using two studies:

\begin{tabular}{|l|}
\multicolumn{1}{|c|}{ Study I } \\
Design of the LetViS \\
Program: needs \\
analysis, program \\
objectives, material \\
development, \\
software design
\end{tabular} \mid $\begin{aligned} & \text { Study II } \\
& \text { Try out the LetViS } \\
& \text { Selective Attention } \\
& \text { Program: subject } \\
& \text { screening, pre-test, } \\
& \text { LetViS treatment, } \\
& \text { test post }\end{aligned}$

\subsection{Study I}

The research design of study I uses an exploratory research approach. Exploration is a research technique still in its identification stage, in such a way that researchers are aware and able to develop concepts and data in accordance with the conditions inherent the field (Sugiyono, 2016). In the process the research made use of survey methods to obtain information about the phenomena that exist in the object of research and seek information in an actual and systematic manner.

Purposive sampling technique was used to select samples that are tailored to the objective of the study (Patton, 2015). The sample category was divided into two groups. The first group consisted of children who were diagnosed with ADD owing to their conformity with the characteristic criteria of the study sample. The second group, was made up of normal children, this group was chosen to obtain data representing non-ADD children with attention development in the child's phase. In general, the samples consisted of 8-year-old elementary school students in Bandung.

The Instructional System Design approach (Kohl, 1995) was used to design the LetViS program. Needs analysis, program objectives, development of computer materials such as the type of stimulus in the form of letters, letter size and card image, task difficulty level, number of stimulus appearances, determination of reinforcement, determination result score, and determination of computer program software design programmers were also determined.

It is also used to validate the LetViS program design to experts (expert judgment), and aimed at getting input on content from aspects of the LetViS computer program design. This is in line with Goodwin \& Leech (2003) explanation, which explains validation based on content tests derived from analysis by experts on the complied content. The assessment includes items, compilation of tasks and processes undertaken by participants. Validation of the research design was also carried out by testing the LetViS program material design on a child to determine if the presentation of the task was understood, and if the material needed improvement. 


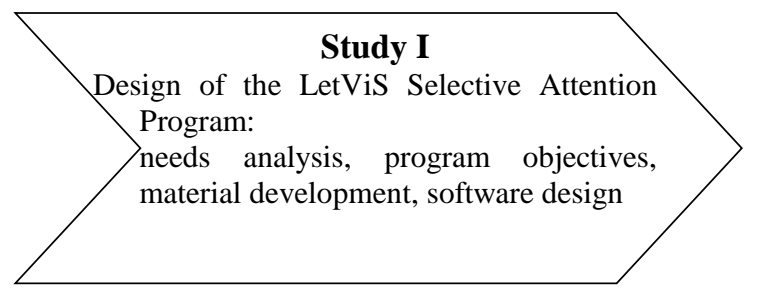

\subsection{Study II}

This study uses a single case time series design, which is a quasi-experimental study to determine the training effects by comparing measurement patterns to dependent variables before and after the training(Christensen, 2007). The purpose of this study was to determine the effect of the LetViS program on selective attention ability.

Table 1: Research Implementation Process

\begin{tabular}{|c|c|c|}
\hline Pre Test & Treatment LetViS & Post Test \\
\hline $\mathrm{X}_{1} \mathrm{X}_{2} \mathrm{X}_{3}$ & $\mathrm{O} 1 \mathrm{O} 2 \mathrm{O} 3$ O4 O5 O6 O7 O8 & $\mathrm{X}_{1} \mathrm{X}_{2} \mathrm{X}_{3}$ \\
\hline
\end{tabular}

The measuring instrument used in the pre or post-test stages is the $\mathrm{d} 2$ test tool. The validity of this instrument was obtained through evidence based on relation to others variables, such as the validity obtained by analysing test scores with external variables that had the same construct as the standard parallel tests. The correlation index had strop colour word and digit symbol modalities with $\mathrm{r}$ values of 0.34 and 0.47 respectively. For reliability, the internal consistency measurements were carried out on 6000 subjects using Spearman Brown's formula with $r=0.92$. The formula shows that the measuring instrument is reliable to measure selective attention ability (Brickenkamp \& Zillmer, 2003).

Single subjects in this study were selected using purposive sampling technique. The children used as subjects of this study experienced GPP if: (1) the inattentive behavioural criteria appeared at least 6 or more times in 6 months, (2) the behavioural criteria for hyperactivity and impulsivity do not appear more than 6 times, (3) the symptoms which causes the disorder appears before the age of seven, 4) symptoms appear in at least 2 settings (home and school), (5) there is clinically clear evidence of a disorder in social, academic or occupational functions, (6) symptoms evolve owing to psychotic and mental disorders.

Other criteria needed for the research subject are as follows: an 8-year-old child who has been diagnosed with ADD with difficulties in ignoring other stimulus disorders, subjects that have an average level of intelligence measured through WISC, and those not undergoing treatment. Stimulant drugs can reduce inattention and impulsive behaviours in children diagnosed with ADD (Barkley, 2015).
To capture the research subject using the above mentioned characteristics, an interview guide used to obtain: an overview of children's inattentive behavior in classrooms and home settings (Satler, 2014), guidance on children's observation in class room which indicators the GPP child behavior during work assignments (Schworm \& Birbaum in Satler, 2002), ADD/ADHD main behavioural questionnaire at school and at home based on DSM-V (APA, 2013), and Weschler Intelligence Scale For Children Test (WISC-Test) were created.

Based on the characteristics and measuring tools of subject selection, only one child out of the numerous research subjects met the required criteria of the research work.

\section{RESULTS}

Results obtained from analysing Study II will be discussed in two parts, namely the analysis of the results of selective attention skills during the LetViS program training and analysis of the results of selective attention skills in the pre-test and post-test measurement stages.

\subsection{Study I}

\subsubsection{Goals Setting}

The general purpose of the selective attention design of the LetViS program is to increase the ADD child ability to pay attention to stimuli that are relevant to the task and improve their ability of to ignore irrelevant stimuli.

\subsubsection{Preparation of the LetViS Program Task Material}

The results of a survey of five ADD and non-ADD children, was carried out. This result will be aimed at obtaining data about the stimulus that will be used in carrying out the training. A questionnaire was answered by the subject to determine a similar letter shape and choose a card size that was comfortable and clearly seen by the child.

Capital letters are the recommended form of letters to be presented in the LetViS program. The used letters are $\mathrm{O}, \mathrm{Q}, \mathrm{C}, \mathrm{D}$. The similarity of these letters is a visual component of the structure from the angle of geometry that dominates the curved shape of the letters. Based on the results of the research conducted by Simpson, I.C., (2013) correlation values (r) are similar in the following letter form: C-O (0.380), D-O (0.342), Q-O (0.383). Child searches between target letters and non-target letters have the same form of demanding the ability inherent the behaviour inhibitor system.

The font type commonly used in writing is San serif (Arial). This is used to the fact that it easily detects stimulus when displayed on the monitor screen, owing to the simplicity of its screen. From the survey results it can 
be seen that the the number of shapes in the series of letters presented in the card image is 7 . The saccadic eye movement process influences the perceptual span ability, such as the number of letters and spaces captured during the fixation process. This usually includes 3 to 15 letters to the left and 15 letters to the right of the letter we are looking at. The size of the letters and spaces is important to get the level of legibility of the visual stimulus clearly. Space gives tolerance to proportional optical views.

Table 2. Results of the Letter Usage Selection Survey

\begin{tabular}{|l|c|l|c|l|}
\hline Letter & \multicolumn{2}{|c|}{ Children with ADD } & \multicolumn{2}{c|}{ Non ADD Children } \\
\hline & Amount & Percentage & Amount & Percentage \\
\hline Capital & 4 & $80 \%$ & 3 & $60 \%$ \\
\hline Small & 1 & $20 \%$ & 2 & $40 \%$ \\
\hline C - O & 4 & $17,39 \%$ & 4 & $18,18 \%$ \\
\hline D - O & 4 & $17,39 \%$ & 3 & $13,36 \%$ \\
\hline O - Q & 5 & $21,73 \%$ & 5 & $22,72 \%$ \\
\hline
\end{tabular}

Regarding the size of the card image the child chooses the $7.62 \mathrm{~cm} \times 12.7 \mathrm{~cm}$ card image size, which is the Flick card (Flick, 2010). The presentation of letters should be made on a white card with striking colours, such as red.

\subsubsection{Determination of Level Difficulty}

Flick (2010) provided a level of difficulty in presenting stimulus based on its emergence speed which can improve individual performance. Level 1 was based on the appearance of the target and non-target stimulus every 2 seconds; while Level 2, was based the appearance of the target and non-target stimulus every 1.5 seconds.

\subsubsection{Determining the Duration Time}

The duration of the assignment is obtained by comparing the duration between children with non-GPP and those with GPP in carrying out assignments in a duration of 15 minutes (Dawson \& Guare, 2010)

\subsubsection{Determination of the Number of Stimulus Appearances}

The comparison of the number of questions between the target and non-target card 1: 2. This is based on the general purpose of the training that is to enhance the ability of selective attention which focuses on the child's ability to ignore irrelevant stimuli. Level 1 with a 15 minutes duration, will display 300 questions about stimulus. However, comparing this to stimulus, will display 100 stimulus targets and 200 non- stimuli targets. Level 2 will display 360 questions about stimulus in 15 minutes. Comparing the amount of stimulus that appears consists of 120 target stimuli and 240 non-target stimuli.

\subsubsection{Determination of scoring}

The correct score shows the on-task. Children are able to direct attention and work according to instructions. The correct number of scores is obtained when: pressing the space when the target stimulus appears and not pressing the space when the non-target stimulus appears. Wrong scores indicate off-task. Children's inability to direct attention with reference to completing tasks according to instruction is divided into two types, namely omission error and commission error. The number of false scores is obtained by the child if it fails to press the space when the target stimulus appears (passing / omission) or if it is able to press it when a nontarget (commission) stimulus appears (Head \& Helton, 2012).

\subsubsection{Determination of Sound Effects}

"Yes" or "No" sound when the child gives the right response to stimulus is displayed and is aimed at providing positive and negative immediate reinforcement (Vallet, 1976). Immediate reinforcement is needed in fostering self-awareness, because the child can realize the effective and ineffective behaviour displayed when carrying out the task (Vallet, 1976; Steinberg \& Othmer, 2004)

\subsubsection{Task Instructions for Work}

Flick (2010) explains that instruction to children with GPP must be short, specific and clear. This will help the child repeat the instructions given so that he is able to perform the task correctly. When viewing a picture of a card with the OOOQOOO letter series, press the space bar once. But if you see a picture of a card with OOOCOOO or OOODOOO series of letters, press the space key.

\subsubsection{LetViS Program Software Implementation}

The LetViS software is useful in detecting the program that has been designed optimally. The image below displays the information related to the compiled LetViS program.

The main menu displays the Instructions, Trial, Level 1, Level 2, and Score.

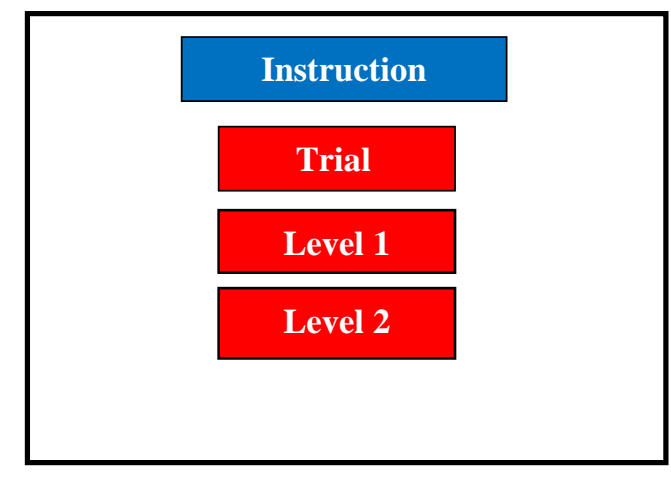




\section{Score}

At each level the task will randomly display the card with the OOOQOOO letter series as the target stimulus and the card image with the letters OOOCOOO or OOODOOO as non-target stimulus.

Figure 3 Target and Non-Target Stimulus (Distractors)

\section{Q000 000Q000 000Q000}

\subsection{Study II}

The LetViS program trial was carried out 8 times. The first to the fourth training was carried out in level one. While the fifth to eighth training meeting was carried out in level two. The psycho-education approach is used in each meeting in three stages, namely the Preparation (Readiness), the Exercise, and the Feedback and Evaluation Stages.

The readiness phase submitted to the research subject aims to prepare the child to focus and be willing to take part in the exercise. It is expected that at this readiness stage, children's interest and feeling can be fostered so that they are willing to be actively involved in the treatment. The next stage is the training phase. In this stage, the child begins to direct himself to see the details of the card image (self-directed action). The child prepares the method of work that he will use by being able to complete this exercise in accordance with the applicable instructions and rules (goal directed behaviour). Repetition of exercises and sequential plans will be information and maintained in the mind of the child (Barkley, 2015). The last stage will be evaluated with feedback given by the child to record the correct score and wrong scores obtained. Children monitor their own behaviours during training by looking at the results of the recorded exercises. Researchers and children conduct discussions and provide feedback that aims to foster self-awareness in them regarding effective and less effective behaviours. In addition, through this feedback, LetViS program training is expected to provide access to easy classroom learning in accordance with the results of the exercise.

This improvement can be seen from the selective attention (SA) score index during the LetViS program training which is presented in the following graph :

From the Figure 3, the selective attention (SA) ability obtained by the research subjects experienced an increase during the LetViS training program. The ability of the child to provide the right response to the target stimulus and the ability to ignore distraction in the form of nontarget stimulus is getting better. The decrease in SA scores occurs in the second training, where the ineffective behaviour displayed during the exercise as complained by the child include drowsiness, changes in sitting position, writhing, and shaking of legs. Subjects got distracted from the laptop screen making them obtain a wrong score. This indicates a decrease in awareness when completing a task. As a result of this decrease in awareness, a decrease in the subject's ability is as a result of distraction. In the evaluation and feedback phase, the subject is aware that when bored he will find it difficult to give the correct response to the stimulus that appears. During the feedback process the child realizes that he will not repeat. In the process of generalizing ineffective behaviours when practicing in a learning situation he must be more concentrated or focused.

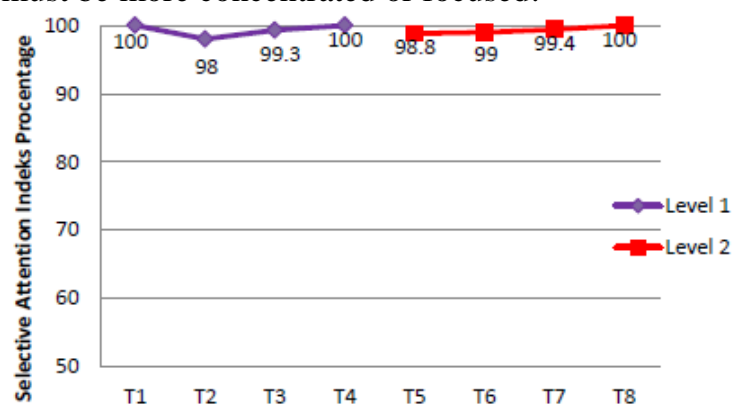

Figure 5. Selective Attention Capability Index in the LetViS Program Training Phase

\subsubsection{Analysis of Selective Attention Ability Results in Pre - Test Post Measurement Phase}

The purpose of this study is to determine the effect of the LetViS program on selective attention ability. To achieve this goal, the TN-E score obtained was compared to the measuring instrument $\mathrm{d} 2$ Test of Attention (dTOA) in the pre-test and test post phases.

Table 4. TN-E Score Pre Test Stage and Test Post

Categorized on Norms of GPP Children Aged 8 Years

\begin{tabular}{cclccl}
\hline Pre & TN-E & ADD & Pos & TN-E & ADD \\
test & Score & Categorized & test & Score & Categorize \\
\hline 1 & 223 & Below & 1 & 384 & Average \\
2 & 303 & Below & 2 & 421 & Above \\
3 & 345 & Below & 3 & 434 & Above \\
Mean & 290 & Below & Mean & 413 & Above
\end{tabular}

Based on the above table in the pre-test stage the subject gets an average TN-E score of 290 points. The condition of a child before getting LetViS training is in the category below the average when compared to a GPP child aged 8 years. When compared to a non GPP children in the borderline category. This illustrates that the ability of the speed and accuracy of the child in doing the task correctly on the target stimulus and ignoring the distraction stimulus that accompanies the task is classified as below average so it needs to be improved. 
At the test post, the TN-E score was increased to 413 points. There is an increase of 123 points from the pretest. Acquisition of children in the pre-test and post-test stages when compared to an increase in categories below the average increased to above-average categories.

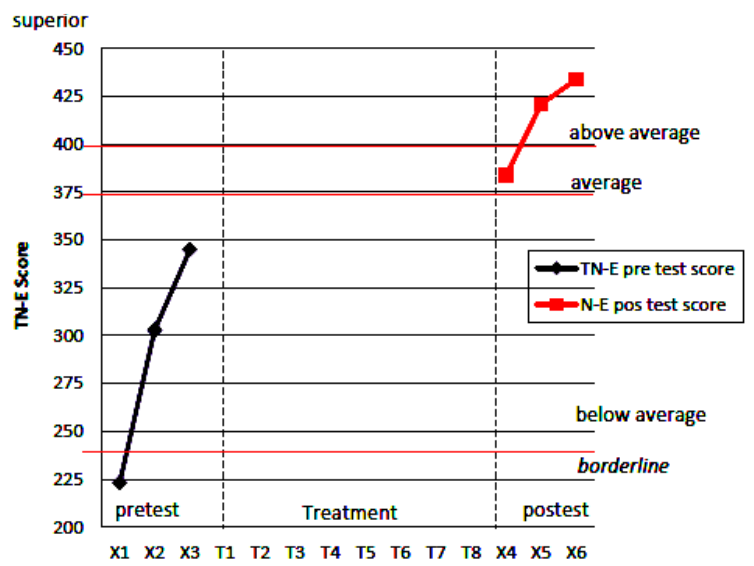

Figure 6. Graph of TN-E Score Pre-Post Stage Test Category Norms of GPP Children Aged 8 Years

Based on the graph above, it can be seen that the TNE score on the pre-test selected drawing subject enables the attention ability to be stable. D2TOA test results of subjects in the pre-test measurements are strongly influenced by the distraction that accompanies the task execution. Ineffective behaviours when working on tasks is displayed by the subject. Such behaviours is influenced by the distraction of thinking that suddenly appears which is unable to withstand curiosity so that he stops working on the task and comments on the error, the amount it works. The second measurement, stops when working on a task time lag between the previous line and the next line. The emergence of these distractions cannot be ignored by the subject, so the score obtained is classified in the borderline category and below the average.

Improvement in children's selective attention ability is seen in the test scored. TN-E score was obtained in the average category. This means that the subject's ability to perform tasks according to instruction is to maintain attention and ability to ignore distraction. This illustrates that the ability of the child's speed and accuracy in carrying out the task correctly stimulus and the ability to ignore the distraction stimulus that accompanies the work after following LetViS program training. This ability is displayed by the subject who applies the effective behavior he obtained from the LetViS program training process to the working condition of the d2TOA during the test post. Effective behavior displayed by the subject such as staying focused when listening to instructions, can refrain the child from internal disruption, such as comments while working on assignments.

\section{CONCLUSION}

The design and training of the Letter Visual Search (LetViS) program can enhance selective attention skills in children under 8 years who experience GPP. The various psychoeducation training phases in LetViS which comprises of, the preparation stage, the training phase, the feedback evaluation stage and the predetermined behavior modification principles, plays a vital role in fostering self-awareness in children which is the basis for making effective behaviour changes. It is recommended that psychologist practitioners can apply LetViS training as a form of treatment for children who experience GPP. It is suggested that the next research design would make use of the control group so that the difference in the results of the LetViS training that occurred between the two research groups can be detected.

\section{REFERENCES}

American Psychiatric Association. (2013). Diagnostic and statistical manual of mental disorders ( $5^{\text {th }} \mathrm{Ed}$ ). Washington DC: American Psychiatric Association.

Simpson, I.C., Mousikou, P., Montoya, J.M., Defior, S.(2013). A letter visual similarity matrix for latin based alphabets. Behavior Research Methods, Instruments, \& Computers, Vol 45 (2), 431-439.

Barkley. R. A. (2015). Attention deficit hyperactivity disorder. A handbook for diagnosis and treatment. Third edition. New York. The Guilford.

Brown, T.E. (2013). Executive function and attention deficit hyperactivity disorder: implication of two conflicting views. International Journal of Disability, Developmental and Education. 53, 35-46. https://doi.or/10.1080/10349120500510024

Casco, C., Tressoldi, P.E. \& Dellantonio.E. (1998). Visual Selective Attention And Reading Efficiency Are Related In Children. Department of General Psychology, University of Padova, Italy.34, 531-546. http://doi.org/10.1016/S0010-9452(08)70512-4

Christensen, L. B. (2007). Experimental methodology. $7^{\text {th }}$ edition. USA : Alyyn \& Bacon.

Dawson, P \& Guare,R.(2010). Executive Skills in Children and Adolescennts : Practical Guide to Assesment and Intervention. New York : The Guilford Press.

Gomes, H., Duff. M., Ramos. M., Molholm. S., Foxe. J.J., Halperin. 2012. Auditory Selective Attention and Processing in Children with Attention-Deficit/ Hyperactivity Disorder. Clinical Neurophysiology.123. 2.

293-302.

doi: https://doi.org/10.1016/j.clinph.2011.07.030

Flick, G.L. (2010). Managing ADHD in the K-8 Classroom. California : Thousand Oaks.

Goodwin, L. D.,\& Leech, N. L. (2003). The meaning of validity in the new standars for educational and psychological 
testing. Measurement and Evalution in Counseling and Development Journal. 36.( 3).

Head, J. \& Helton, W. S. (2012). Natural scene stimuli and lapses of sustained attention. Consciousness and cognition 21(4):1617-1625

Patton, M.Q. (2015), Qualitative research \& evaluation methods . Fourth edition,. California, Sage Publication, Inc.

Sattler, J.M. (2014). Foundation of Behavioral,Social, and Clinical Assessment of Children. Sixth Edition.I. California : Jerome M. Sattler, Publisher, Inc. ISBN 9780970267122.

Schneider, W., \& Shiffrin, R. M. (1977). Controlled and automatic human information processing. I. Detection, search, and attention. Psychological Review, 84(1), 166.

Sohlberg, M.M., \& Mateer, C.A. (2010). APT-III: Attention process training: A direct attention training program for persons with acquired brain injury. Youngville, NC: Lash \& Associates.

Steinberg, M \& Othmer S. (2004). ADD The 20-hour solution. USA: Robert D Reed Publisher.

Sugiyono. (2016). Metode Penelitian Kuantitatif, Kualitatif dan $R \& D$. Bandung : Alfabeta.

Valett, R. E. (1976). Programming Learning Disabilities. California: Fearon Publisher.

Sandford, J.A.(2003). Cognitive training and computers: An Innovative Approach. In: Fine, A.H. and Kotkin, R.A., Eds., Therapist's Guide to Learning and Attention Disorders, Academic Press, London, (pp. 421-441.) http://dx.doi.org/10.1016/B978-012256430-7/50016-8

Veenman, M.V . J., Bavelaar, L., De Wolf, L. \& Van Haaren, M.G. P. (2014). The on-line assessment of metacognitive skills in a computerized learning environment . Learning and Individual Differences , 29, 123 -130. http://dx.doi.org/10.1016/j.lindif.2013.01.003 